\title{
Mechanical and Durability Evaluation of Concrete with Sulfate Solution Corrosion
}

\author{
Feng Ming, ${ }^{1,2}$ You-sheng Deng, ${ }^{1}$ and Dong-qing $\mathrm{Li}^{1}$ \\ ${ }^{1}$ State Key Laboratory of Frozen Soil Engineering, Northwest Institute of Eco-Environment and Resources, \\ Chinese Academy of Sciences, Lanzhou 730000, China \\ ${ }^{2}$ Qinghai Research and Observation Base, Key Laboratory of Highway Construction \& Maintenance Technology in Permafrost Region, \\ Xining 810000, China
}

Correspondence should be addressed to Feng Ming; mf0329@163.com

Received 10 October 2016; Accepted 21 November 2016

Academic Editor: Francesco Caputo

Copyright (C) 2016 Feng Ming et al. This is an open access article distributed under the Creative Commons Attribution License, which permits unrestricted use, distribution, and reproduction in any medium, provided the original work is properly cited.

\begin{abstract}
Concrete material has been a choice for the construction structures, even in the cold regions and saline zone. However, these environmental factors have critical damaging effect on the concrete characters. Consequently, this damage will decrease the servicing time of the concrete construction within this environment. In order to evaluate the durability of concrete, the behavior of concrete specimens under the sulfate solution corrosion attacks was studied in this presented work. Two groups of the specimens were immersed into the sulfate solutions with a concentration of $10 \%$ and $20 \%$, respectively. The strength development of the specimens under different immersing time was studied. Based on Fick's law, a steady diffusion equation for sulfate ions in concrete was presented, and the depth of penetration of the attacking sulfate ions was also determined. Based on the depth of penetration and the definition of damage, a damage model for concrete material is developed and a new equation (strength-time) describing the chemical corrosion concrete material is proposed. Results show that the suggested analytical methods can quantify the damage process of concrete under sulfate attack, and the power laws damage developing formula can be used to describe the damage development of the concrete construction subjected to chemical corrosion.
\end{abstract}

\section{Introduction}

With a global production over 10000 million tons per year [1], the concrete material has been one of the most famous manmade materials in civil engineering. With the developing of concrete technology, the concrete material has been a choice for the construction structures, which is exposed to the extreme conditions (cold regions, saline zone) [2, 3]. However, because the durability is not strong enough to withstand the applied loads in this environment after the concrete structures constructed in the saline zone about $5 \sim 10$ years, the concrete structures need to be repaired or replaced $[4,5]$. According to the statistics, spending on repair and replacement of deteriorated concrete structures is astronomical. Therefore, the durability problem has been a social focal problem due to the poor performance of concrete caused by various factors $[6,7]$. Recently, with the project (China Western Development) implementation, many constructions of infrastructure including energy, transport, and telecommunications facilities and other key projects will be built up in the saline zone. Consequently, there is an urgent need for a better understanding of the durability of concrete structure, especially when the concrete structures were placed in the saline zone.

The domestic and overseas scholars have studied the durability of concrete under different environmental conditions [8-13]. The previous results pointed out that the key affecting factors for the durability of concrete structure are material factor, environmental factor, and construction factor $[8,9,14]$. The environmental factors such as physical and chemical factors [8], freezing-thawing action [10], and sulfate attack $[9,11]$ have a critical effect on the durability of concrete. Compared to the freezing-thawing action and the continuous immersing, the wet-dry cycling is the most primary factor, which decreases the durability of concrete [15]. Thus, more attention has been focused on the wet-dry cycling action on the durability of concrete $[16,17]$. However, single attacks 


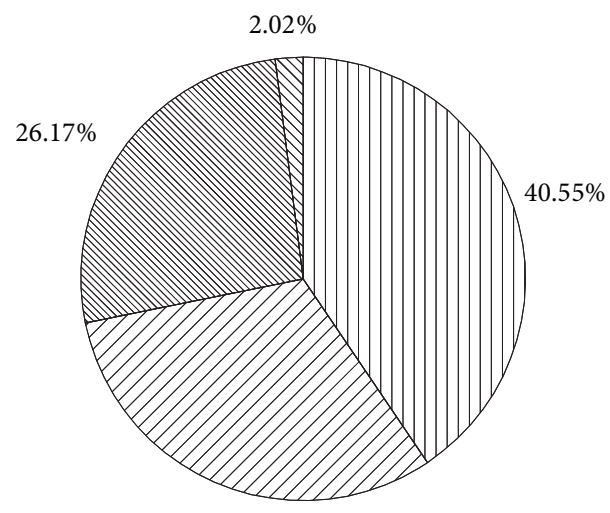

$31.26 \%$

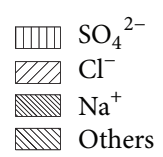

FIgURE 1: Ion contents in soil from Qinghai-Tibet Plateau.

tested in laboratory conditions yield different results than what may actually be experienced in field applications, where multiple deterioration types are occurring simultaneously [8]. According to the field investigation, the contents of $\mathrm{SO}_{4}{ }^{2-}, \mathrm{Cl}^{-}$, and $\mathrm{Na}^{+}$ions were obtained, as shown in Figure 1. Consequently, most of the studies about the concrete deterioration were focused on anticorrosion of concrete against the sulfate solution $[5,16]$. For the abovementioned, the durability of concrete immersed into the sulfate solution is seldom considered. Because the long-term immersion in the salt condition has an influence on the concrete deterioration, thus, a study of concrete members (such as piles) immersed into the sulfate solution is an important aspect of engineering durability problems.

In order to investigate the durability of concrete subjected to external salt attack, the durability tests of concrete were conducted in laboratory and field $[9,12,18]$. Based on these test results, the damage mechanism of concrete was analyzed. However, the tests were carried out in a limited time. As a result, the results can not reflect the long-term performance of the concrete $[6,9]$. Thus, the deterioration mechanism model, which is used to predict the concrete durability, was presented. Based on these deterioration mechanism models, the long-term performances, such as load-bearing capacity and durability, can be evaluated [12, 19]. Generally, these models mainly focus on the following aspects: the process of the sulfate ion diffusion, the increment of the expansion strain and stress, and the cracking of a concrete plate [20-22]. However, due to the ideal assumptions of these deterioration mechanism models, the predicted result has a large difference with the testing result [23]. Furthermore, in many practical applications, not only do chemical attacks occur in the concrete structures, but also simultaneously the actions of chemical attacks, freezing-thaw, and mechanical stresses take place $[8,10,14]$. Thus, the deterioration mechanism of concrete is very complex, especially when there are interactions between the concrete constructions and the environment
[24]. As a result, these models mentioned above, which try to build a deterioration model from the aspect of microstructure physical and chemical characteristics, are not suitable for predicting the service life of the concrete constructions $[23,24]$. The engineering practice indicates that concrete deterioration is a progressive reduction in properties and ultimately makes concrete no longer serviceable for its intended application [16]. Motivated by this phenomenon, based on the results of systematic experiments, the damage development of concrete subjected to freezing-thawing cycles and/or wet-dry cycles and/or chemical attack was studied by the damage mechanics principles $[21,25,26]$. Of all, the long-term performance is a critical factor for service life prediction. Thus, it is important to find a reasonable method to predict the longterm performance of the concrete constructions.

After reviewing the history and the present situation of the investigation on the concrete durability, it can be found that there are many works that have been done about the durability of concrete. This paper presents aspect of the research performed in the laboratory using natural testing procedures and looking at the deterioration of sulphane ingress. The depth of penetration of the attacking sulphane ions was determined after a certain time. Based on the concept of the damage degree, a new equation (strengthtime) describing the chemical corrosion concrete material is proposed. On the basis of the experimental results, the prediction model was obtained and this model can be used to predict the durability of the concrete construction.

\section{Experimental Designs}

\subsection{Characteristics of Concrete Mixtures}

2.1.1. Cement. The cement is ordinary Portland cement (PO 42.5) produced by Qilianshan Corporation in Gansu Province, China. The performance index of the used cement is shown in Table 1.

2.2. Sample Preparing. The ratio mass (water): mass (cement) is 0.45 , the ratio mass (sand): mass (cement) is 1.23 , and the ratio mass (stones) : mass (cement) is 2.63 . The details of the concrete mixture are listed in Table 2.

All specimens were prepared as cube of $100 \mathrm{~mm} \times$ $100 \mathrm{~mm} \times 100 \mathrm{~mm}$ in the laboratory. Raw materials included Portland cement, silica sand, stone, and water. All specimens were cured for one day in nature condition before being demoulded and for another 27 days cured at $20 \pm 1^{\circ} \mathrm{C}$ with a relative humidity at $95 \pm 5 \%$.

2.3. Continuous Immersing Tests. In order to measure the sulfate erosion damage of the concrete specimens, $\mathrm{Na}_{2} \mathrm{SO}_{4}$ solution was chosen as the sulfate liquor, and two concentrations of $10 \%$ and $20 \%$ were considered. After all the specimens were cured for 28 days, the specimens were immersed into the sulfate solution. During the continuous immersing tests, the sulfate solution was changed once a month to ensure the mass fraction unchanged. After immersing $0 \mathrm{~d}, 30 \mathrm{~d}, 60 \mathrm{~d}, 90 \mathrm{~d}$, $120 \mathrm{~d}, 180 \mathrm{~d}, 270 \mathrm{~d}, 360 \mathrm{~d}$, and $450 \mathrm{~d}$, the specimens are picked out, and then the compressive strength test was conducted, 
TABle 1: PO 42.5 performance index of Portland cement.

\begin{tabular}{lcccccccc}
\hline $\begin{array}{l}\text { Specific } \\
\text { surface area } \\
{\left[\mathrm{m}^{2} \cdot \mathrm{kg}^{-1}\right]}\end{array}$ & $\begin{array}{c}\text { Chloride ion } \\
{[\%]}\end{array}$ & $\begin{array}{c}\text { Alkali } \\
\text { content [\%] }\end{array}$ & $\begin{array}{c}\text { Sulphur } \\
\text { trioxide [\%] }\end{array}$ & $\begin{array}{c}\text { Ignition loss } \\
{[\%]}\end{array}$ & \multicolumn{2}{c}{ Setting time [min] } & \multicolumn{2}{c}{$\begin{array}{c}\text { Compressive strength } \\
{[\mathrm{MPa}]}\end{array}$} \\
\hline 347 & 0.012 & 0.43 & 2.44 & 1.52 & 185 & Final & 325 & 21.7 \\
\hline
\end{tabular}

Sand: well-graded medium river sand, the fineness modulus being 2.7 ; stones: continuous grading gravel, $5 \sim 20 \mathrm{~mm} ; \mathrm{Na}_{2} \mathrm{SO}_{4}$ : analytical reagent with a quality fraction of $99.28 \%$ and the relative molecular mass being 142.04 ; the running water was used to mix these raw materials.

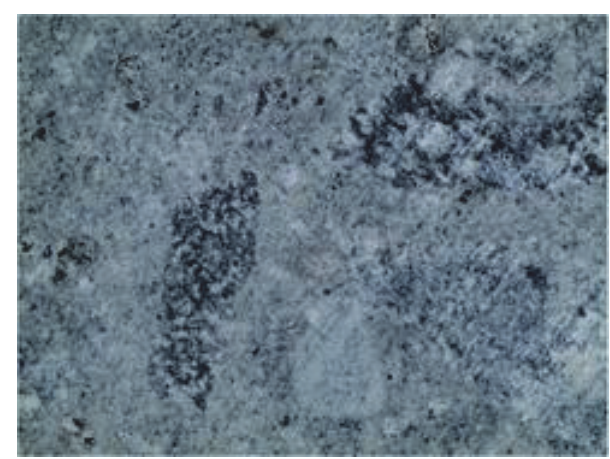

(a) One month

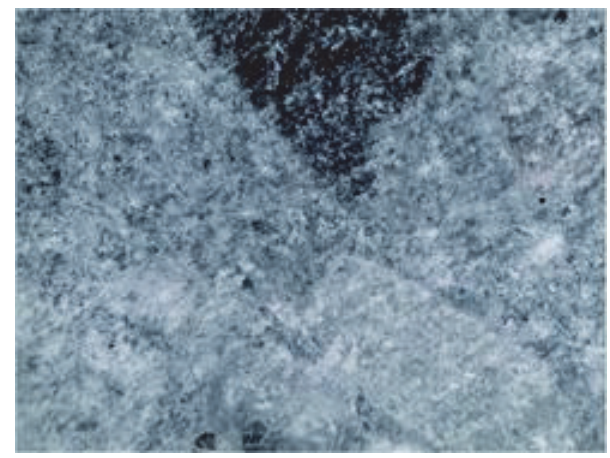

(c) Eight months

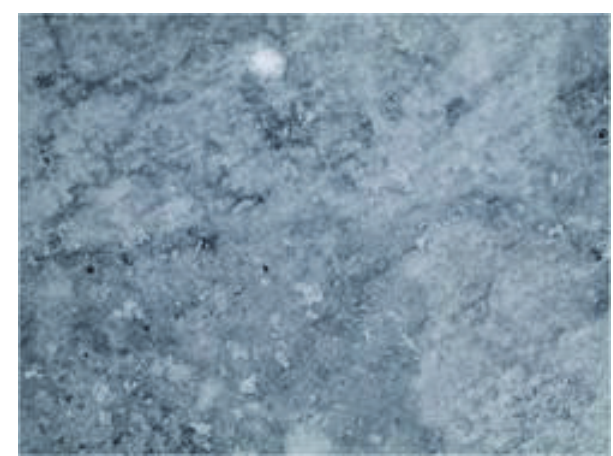

(b) Three months

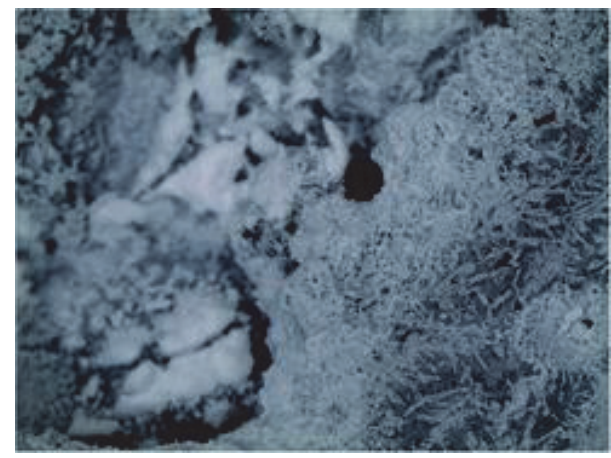

(d) Fifteen months

FIGURE 2: Microstructures of concrete specimens subjected to different immersing time.

TABLE 2: Concrete mixture.

\begin{tabular}{lccccc}
\hline $\begin{array}{l}\text { Water } \\
{[\mathrm{kg}]}\end{array}$ & $\begin{array}{c}\text { Cement } \\
{[\mathrm{kg}]}\end{array}$ & $\begin{array}{c}\text { Sand } \\
{[\mathrm{kg}]}\end{array}$ & $\begin{array}{c}\text { Stone } \\
{[\mathrm{kg}]}\end{array}$ & W/C & $\begin{array}{c}\text { Sand } \\
\text { percentage [\%] }\end{array}$ \\
\hline 205 & 455 & 562 & 1195 & 0.45 & 32 \\
\hline
\end{tabular}

with a loading rate of $0.5 \mathrm{MPa} / \mathrm{s}$. During the test events, when the two duplicate samples' tolerance bias is over $5 \mathrm{MPa}$, this result is rejected.

\section{Test Result}

Figure 2 shows the microstructure of concrete specimens subjected to different immersing times in sulfate solution with a concentration of $10 \%$. As shown in Figure 2(a), there is no ettringite crystal that can be seen in the pores after one month of immersion. With the increasing of immersing time, a little amount of ettringite crystals can be seen in the pores after immersion for three months (Figure 2(b)). With the amount of ettringite crystals continuously increasing with immersion time, the sulfate solution has little destroying effect on the concrete and is accompanied by small fracture and convex protrusion (Figure 2(c)). After immersion for eight months, massive ettringite crystals and gypsum crystals could be noted in the pores (Figure 2(c)). It is well known that when the corrosion products are formed enough, the concrete has to bear the expansion stress [3]. If the expansion stress generated by the expansive products exceeds the tensile strength of concrete, the fracture may occur from the surface to the internal region [18], as shown in Figure 2(d). From the abovementioned, it can be concluded that with the increasing of immersing time the sulfate attack has an obviously destroying effect on the concrete structure.

From Figure 2, the results indicate that the sulfate solution is decreasing the durability of the concrete. However, the damage level can be not determined. In order to analyze the 


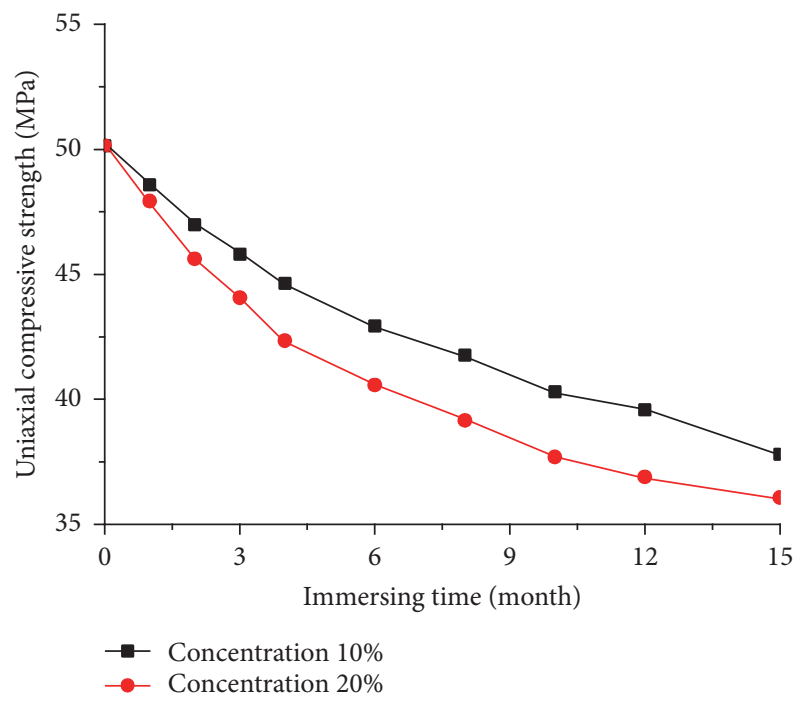

Figure 3: Uniaxial compressive strength results.

damage mechanism of concrete under sulfate solution environment, the uniaxial compressive tests were conducted and the uniaxial compressive strength results are presented in Figure 3. As shown in Figure 3, the uniaxial compressive strength decreases with the increasing of immersing time whatever in the low or high concentration environment. Moreover, concentration of $20 \%$ has more serious damage than the concentration of $10 \%$. As the sulfate attack occurs continuously in the concrete, the damage caused by chemical corrosion, especially the ettringite crystals, results in more porous structure in concrete [18]. Due to the increasing of permeability, the sulfate solution can more easily penetrate into the interior; as a result, the porosity is increasing and the effective area is decreasing. Consequently, it is accelerating the process of deterioration, and the deterioration manifests as the uniaxial compressive strength decreasing with immersing time.

According to the definition of the damage degree, the following formula can be obtained [27]:

$$
D_{i}=1-\frac{\sigma_{i}}{\sigma_{0}}
$$

where $D_{i}$ is the damage degree of concrete after certain immersing time; $\sigma_{i}$ is the uniaxial compressive strength of concrete after certain immersing time; $\sigma_{0}$ is the initial uniaxial compressive strength of concrete.

Figure 4 shows the damage development of concrete subjected to different sulfate solution concentrations. It can be seen clearly from Figure 4 that the damage degree of concrete in both sulfate solutions increased with the immersing time. Furthermore, the experimental results showed that the damage degree of concrete immersing to the concentration of $20 \%$ is higher than the concentration of $10 \%$. With the damage developing, the bearing of the concrete construction is decreasing. When the damage reaches a certain degree, the concrete constructions will fail completely.

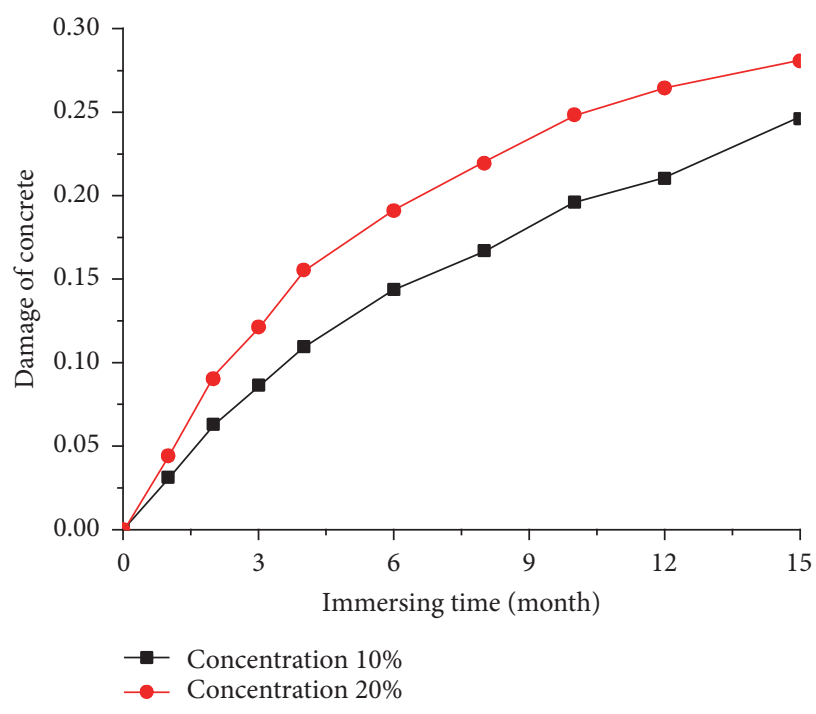

FIGURE 4: Damage developing with the immersing time.

\section{Damage Developing Model for Chemical Corrosion of Concrete}

It is well known that the concrete constructions, such as piles, were designed with a long service time. As a result, much attention has been paid to the durability of concrete, especially including the sulfate erosion $[6,8,14]$. Of course, the uniaxial compressive strength is an important parameter for determining the concrete durability. In this section, based on Fick's law, a steady diffusion equation of sulfate ions is presented. With the damage developing equation of concrete subjected to sulfate environment, a systematic theory for the prediction of service life of concrete constructions was presented.

The process of concrete degradation is simplified with three important assumptions as follows:

(1) Microdefects and hydration product of $\mathrm{SO}_{2}{ }^{-4}$ are distributed evenly in the concrete.

(2) The expansion of the solid product is treated as a uniform expansion.

(3) Ignoring the $\mathrm{SO}_{2}{ }^{-4}$ concentration varies with time in the corrosion areas.

4.1. Process of Ion Diffusion. The concrete material is considered as two-phase material, which consists of a matrix and pores. Thus, the ion can migrate in the concrete constructions and the penetration depth increased with the increasing of immersing time, as shown in Figure 5.

According to Fick's law, the following equation can be obtained:

$$
J(x)=\frac{\mathrm{d} m}{\mathrm{~d} t}=-L^{2} k \frac{\partial c}{\partial x},
$$

where $J(x)$ is the erosion ion flux; $m$ is the mass of the ion which diffuses into the concrete; $t$ is time in months; $L$ is the length of the research area; $k$ is the diffusion coefficient; 


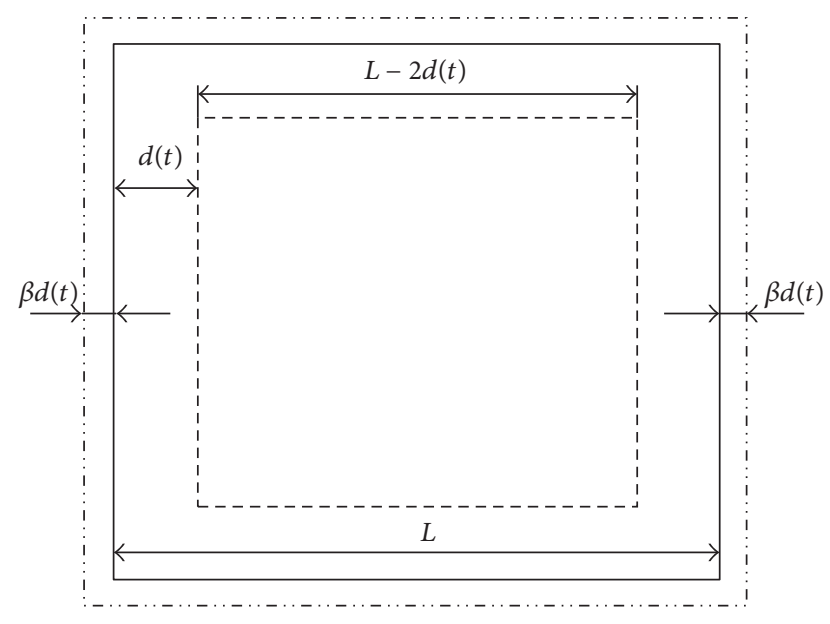

FIGURE 5: Cross section of the chemical attacked concrete specimen.

$c$ is the solution concentration in the corrosion layer; $x$ is coordinate.

Equation (2) can be written in another form:

$$
\partial c=-\frac{J(x)}{L^{2} k} \partial x
$$

Integrating (3), we obtain

$$
\int_{\mathcal{c}_{0}}^{0} \partial c=-\int_{0}^{d(t)} \frac{J(x)}{L^{2} k} \partial x,
$$

where $c_{0}$ is the solution concentration at the surface of the corrosion layer; $d(t)$ is the diffusible depth.

Rewriting (4) gives

$$
J(x)=\frac{L^{2} k c_{0}}{d(t)} .
$$

Substituting (2) into (5),

$$
\frac{\partial c}{\partial x}=-\frac{c_{0}}{d(t)}
$$

Supposing that the mass of the hydration product of $\mathrm{SO}_{2}{ }^{-4}$ in unit area is $n$, then the mass of the hydration product of $\mathrm{SO}_{2}{ }^{-4}$ in $L^{2} \mathrm{~d} x$ can be calculated:

$$
n L^{2} \mathrm{~d} x=-L^{2} k \frac{\partial c}{\partial x} \mathrm{~d} t
$$

Substituting (6) into (7) and integrating, then the diffusible depth can be described as follows:

$$
d(t)=\sqrt{\frac{2 k c_{0} t}{n}} .
$$

4.2. Process of Damage Developing. During the sulfates corrosion, the penetration of aggressive media leads to an increase of the porosity of the material. It is assumed that, due to the increasing of the porosity, there is an expansion coefficient of the attacked area as shown in Figure 5 and (9). At any time $t$, the length of the area can be drawn by the following formula:

$$
L(t)=L+2 \beta d(t)
$$

The length of noncorrosive areas is

$$
l(t)=L-2 d(t) .
$$

On the basis of certain definitions of macrophenomenological damage mechanics, then, the damage degree $D$ of the whole area $A$ can be obtained by [27]

$$
D=\frac{\left(A_{1} D_{1}+A_{0} D_{0}\right)}{A},
$$

where $A$ is the area of the sample and $A=L^{2} ; A_{0}$ is the area of the noncorrosive parts and $A_{0}=(L-2 d(t))^{2} ; D_{0}$ is the damage degree of the noncorrosive parts; $A_{1}$ is the area of the corrosive parts and $A_{1}=(L+2 \beta d(t))^{2}-A_{0} ; D_{1}$ is the damage degree of the corrosive areas.

Changing (11) in another form,

$$
\begin{aligned}
D= & D_{0}+\frac{4 d(t)\left[(1+\beta) D_{1}-D_{0}\right]}{L} \\
& +\frac{4 d(t)^{2}\left[\left(\beta^{2}-1\right) D_{1}+D_{0}\right]}{L^{2}} .
\end{aligned}
$$

Substituting (8) into (12),

$$
\begin{aligned}
D= & D_{0}+\frac{4 \sqrt{2 k c_{0} t / n}\left[(1+\beta) D_{1}-D_{0}\right]}{L} \\
& +\frac{4\left(\sqrt{2 k c_{0} t / n}\right)^{2}\left[\left(\beta^{2}-1\right) D_{1}+D_{0}\right]}{L^{2}} .
\end{aligned}
$$

Due to the parameters $D_{0}, D_{1}, L, k, c_{0}, n, \beta$ in (12) that can be determined by the laboratory test, thus, the damage developing of concrete is only depending on the immersing time. Consequently, the damage equation can be rewritten as

$$
\begin{aligned}
D= & D_{0}+\frac{4 \sqrt{2 k c_{0} / n}\left[(1+\beta) D_{1}-D_{0}\right]}{L} t^{1 / 2} \\
& +\frac{8 k c_{0}\left[\left(\beta^{2}-1\right) D_{1}+D_{0}\right]}{n L^{2}} t .
\end{aligned}
$$

After the parameters $D_{0}, D_{1}, L, k, c_{0}, n, \beta$ were determined, the coefficients of $t^{1 / 2}$ and $t$ in (14) can be determined. Thus, (14) can be simplified as

$$
D=D_{0}+b_{1} t^{1 / 2}+b_{2} t
$$

where $b_{1}, b_{2}$ are the experimental constants, corresponding to the concrete characteristic.

For the porous materials, such as soil, rocks, and concrete, because they consist of a matrix and pores, these materials always have initial damage. For the engineering purpose, it is 


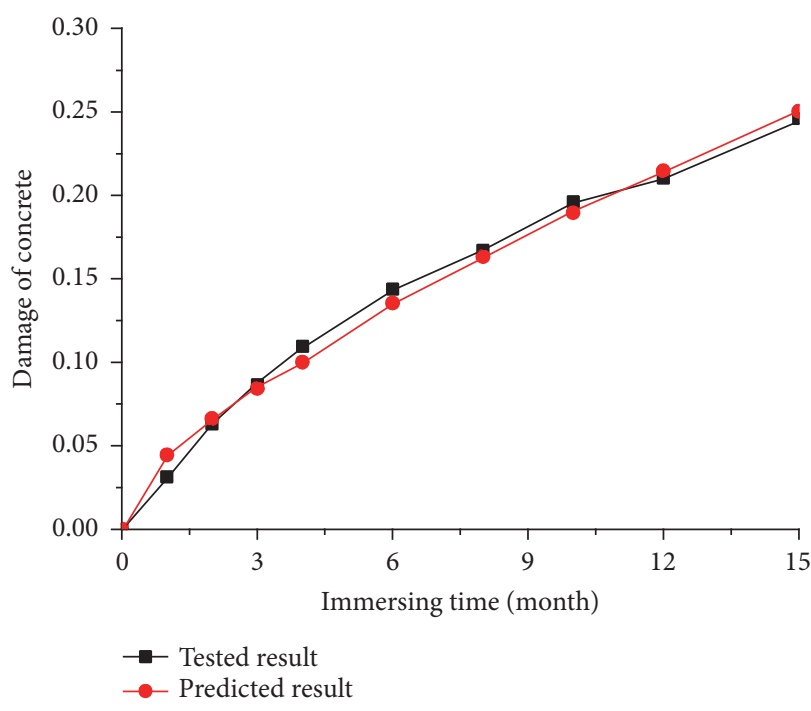

(a) Concentration of $10 \%$

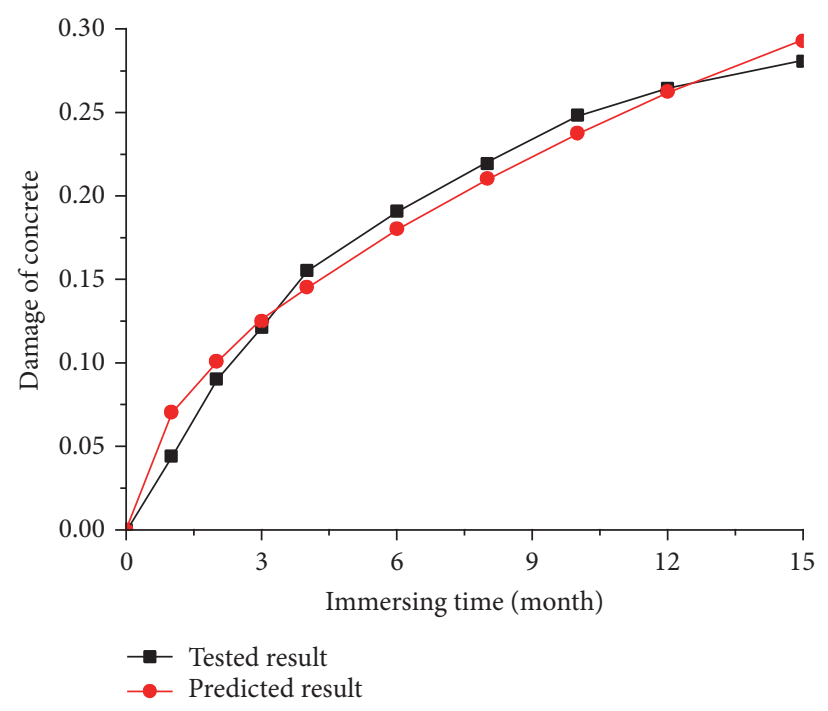

(b) Concentration of $20 \%$

Figure 6: Comparison result between the tested result and the predicted result.

TABLE 3: Regression results for the corrosion of the concrete immersed into $10 \%$ and $20 \%$ sulfate solutions.

\begin{tabular}{lcc}
\hline Concentration [\%] & Regression equation & Standard deviation \\
\hline 10 & $D_{\mathrm{rd}}=0.0391 t^{1 / 2}+0.0055 t$ & 0.028 \\
20 & $D_{\mathrm{rd}}=0.0685 t^{1 / 2}+0.0021 t$ & 0.067 \\
\hline
\end{tabular}

more convenient to use the damage degree $D_{\text {rd }}$, which can be described as follows:

$$
D_{\mathrm{rd}}=D-D_{0}=b_{1} t^{1 / 2}+b_{2} t
$$

According to the previous studies $[6,14,21]$, chemical corrosion can lead to an increase of the porosity and a decrease of the matrix volume of the concrete materials. Equation (14) was derived from the damage theory, which is the effective working parts decreasing with time. Thus, formula (14) including formulas (15) and (16) can be used to evaluate these corrosion effects on concrete materials. On the basis of the experimental damage developing results (Figure 4), the formulas describing the effects of chemical corrosion attacks with concrete construction immersed into sulfate solutions have been obtained by means of regression. The regression result is shown in Table 3 and Figure 6.

On the basis of the experimental result and the presented model, the comparison result between the tested result and the predicted result is shown in Figure 6. As shown in Figure 6, the theoretically derived power law (statistical regression) is complied with the tested results. The standard deviations between the tested results and predicted results are less than $10 \%$ in these two cases. This indicates that the predicted value is well in agreement with the measurement results. Consequently, the presented model is suitable for describing the effect of chemical corrosion attacks with concrete.

\section{Conclusions}

In order to investigate the deterioration mechanism of the concrete materials used in salt regions, two groups of concrete specimens were immersed into sodium sulfate solution with two concentrations of $10 \%$ and $20 \%$. On the basis of the experimental result, a damage developing model of concrete was derived. As a result, the following conclusions can be drawn:

(1) The damage degree of the concrete is increasing with the immersion time, and the macro damage features are more clear. As a result, the concrete has obvious deterioration due to the severe environmental conditions.

(2) The depth of penetration of the corrosive salt solutions increasing with the immersing time increased. Furthermore, the velocity of penetration depends on the initial concentration, the properties, and the structure of the materials.

(3) Based on the relationship between the depth of penetration and the damage degree, the damage developing formula was derived and the power laws can be used to describe the damage development of the concrete construction subjected to chemical corrosion.

\section{Competing Interests}

The authors declare that they have no competing interests.

\section{Acknowledgments}

This work is supported by the National Natural Science Foundation of China (no. 41271080), the Key Research Program of Frontier Sciences of Chinese Academy of Sciences (QYZDYSSW-DQC015), and the Funding of the State Key Laboratory of Frozen Soil Engineering (no. SKLFSE-ZT-17). 


\section{References}

[1] A. Hasanbeigi, L. Price, and E. Lin, "Emerging energy-efficiency and $\mathrm{CO}_{2}$ emission-reduction technologies for cement and concrete production: a technical review," Renewable and Sustainable Energy Reviews, vol. 16, no. 8, pp. 6220-6238, 2012.

[2] S. Chatterji, "Aspects of the freezing process in a porous material-water system: part 1 . freezing and the properties of water and ice," Cement and Concrete Research, vol. 29, no. 4, pp. 627-630, 1999.

[3] Y. Gao, J. Zhang, and Y. D. Han, "Decay of fracture parameters of concrete under sulfate environments," Journal of Building Materials, vol. 14, no. 4, pp. 465-477, 2011.

[4] J. A. Hartell, A. J. Boyd, and C. C. Ferraro, "Sulfate attack on concrete: effect of partial immersion," Journal of Materials in Civil Engineering, vol. 23, no. 5, pp. 572-579, 2011.

[5] D. Niu, L. Jiang, and Q. Fei, "Deterioration mechanism of sulfate attack on concrete under freeze-thaw cycles," Journal Wuhan University of Technology, Materials Science Edition, vol. 28, no. 6, pp. 1172-1176, 2013.

[6] A. Neville, "The confused world of sulfate attack on concrete," Cement and Concrete Research, vol. 34, no. 8, pp. 1275-1296, 2004.

[7] E. Peris Mora, "Life cycle, sustainability and the transcendent quality of building materials," Building and Environment, vol. 42, no. 3, pp. 1329-1334, 2007.

[8] E. Holt, M. Ferreira, H. Kuosa, and M. Leivo, "Performance and durability of concrete under effect of multi-deterioration mechanisms," Journal of the Chinese Ceramic Society, vol. 43, no. 10, pp. 1420-1429, 2015.

[9] H. L. Zhang, Y. F. Zhu, and J. C. Han, "Study of the durability of partially-exposed concrete in chloride saline soil areas of Qinghai Province," Journal of Hefei University of Technology, vol. 38, no. 4, pp. 804-809, 2015.

[10] W. J. Yan, F. J. Niu, X. J. Zhang et al., "Advances in studies on concrete durability and countermeasures against freezingthawing effects," Sciences in Cold and Arid Regions, vol. 6, no. 4, pp. 398-408, 2014.

[11] C. Faella, C. Lima, E. Martinelli, M. Pepe, and R. Realfonzo, "Mechanical and durability performance of sustainable structural concretes: An Experimental Study," Cement and Concrete Composites, vol. 71, pp. 85-96, 2016.

[12] L. Tang, P. Utgenannt, and D. Boubitsas, "Durability and service life prediction of reinforced concrete structures," Journal of the Chinese Ceramic Society, vol. 43, no. 10, pp. 1408-1419, 2015.

[13] J. M. Aldred and A. Castel, "Chloride penetration after field exposure compared with estimates from service life prediction models," in Proceedings of the RILEM International Workshop on Performance-Based Specification and Control of Concrete Durability, RILEM PRO 089, pp. 143-150, Zagreb, Croatia, June 2014.

[14] R. Gao, Q. Li, and S. Zhao, "Concrete deterioration mechanisms under combined sulfate attack and flexural loading," Journal of Materials in Civil Engineering, vol. 25, no. 1, pp. 39-44, 2013.

[15] R. D. Cody, A. M. Cody, P. G. Spry et al., Reduction of Concrete Deterioration by Ettringite Using Crystal Growth Inhibition Techniques, Iowa State University, Iowa, IA, USA, 2001.

[16] H. L. Wang, Y. S. Dong, X. Y. Sun, and W. L. Jin, "Damage mechanism of concrete deteriorated by sulfate attack in wet-dry cycle environment," Journal of Zhejiang University (Engineering Science), vol. 46, no. 7, pp. 1255-1261, 2012.
[17] Z. Zhang, M. Thiery, and V. Baroghel-Bouny, "Numerical modelling of moisture transfers with hysteresis within cementitious materials: verification and investigation of the effects of repeated wetting-drying boundary conditions," Cement and Concrete Research, vol. 68, pp. 10-23, 2015.

[18] M. T. Bassuoni and M. L. Nehdi, "Durability of selfconsolidating concrete to different exposure regimes of sodium sulfate attack," Materials and Structures, vol. 42, no. 8, pp. 10391057, 2009.

[19] J. Marchand, E. Samson, Y. Maltais, and J. J. Beaudoin, "Theoretical analysis of the effect of weak sodium sulfate solutions on the durability of concrete," Cement and Concrete Composites, vol. 24, no. 3-4, pp. 317-329, 2002.

[20] S. Ahmad, "Reinforcement corrosion in concrete structures, its monitoring and service life prediction-a review," Cement and Concrete Composites, vol. 25, no. 4-5, pp. 459-471, 2003.

[21] U. Schneider and S.-W. Chen, "Modeling and empirical formulas for chemical corrosion and stress corrosion of cementitious materials," Materials and Structures, vol. 31, no. 10, pp. 662-668, 1998.

[22] T. Cho, "Prediction of cyclic freeze-thaw damage in concrete structures based on response surface method," Construction and Building Materials, vol. 21, no. 12, pp. 2031-2040, 2007.

[23] Y. P. Du, Y. Yao, and L. Wang, "Research progress on the prediction of concrete's service life based on freeze-thaw damage," Journal of Yangtze River Scientific Research Institute, vol. 31, no. 4, pp. 77-84, 2014.

[24] W. Sun and C. W. Miao, The Theory and Technology of Modern Concrete, Science Press, Beijing, China, 2012.

[25] Q. H. Xiao, D. T. Niu, and W. P. Zhu Wen, "Strength degradation model and durability service life prediction of concrete in freezing-thawing circumstance," Building Structure, vol. 41, no. 2, pp. 203-207, 2011.

[26] M. Leivo, E. Sistonen, F. Al-neahawy et al., "Effect of interacted deterioration parameters on service life of concrete structures in cold environments," VTT Research Report VTT-R-09119-11, 2011.

[27] D. T. Niu, Durability and Life Forecast of Reinforced Concrete Structure, Science Press, Beijing, China, 2003. 

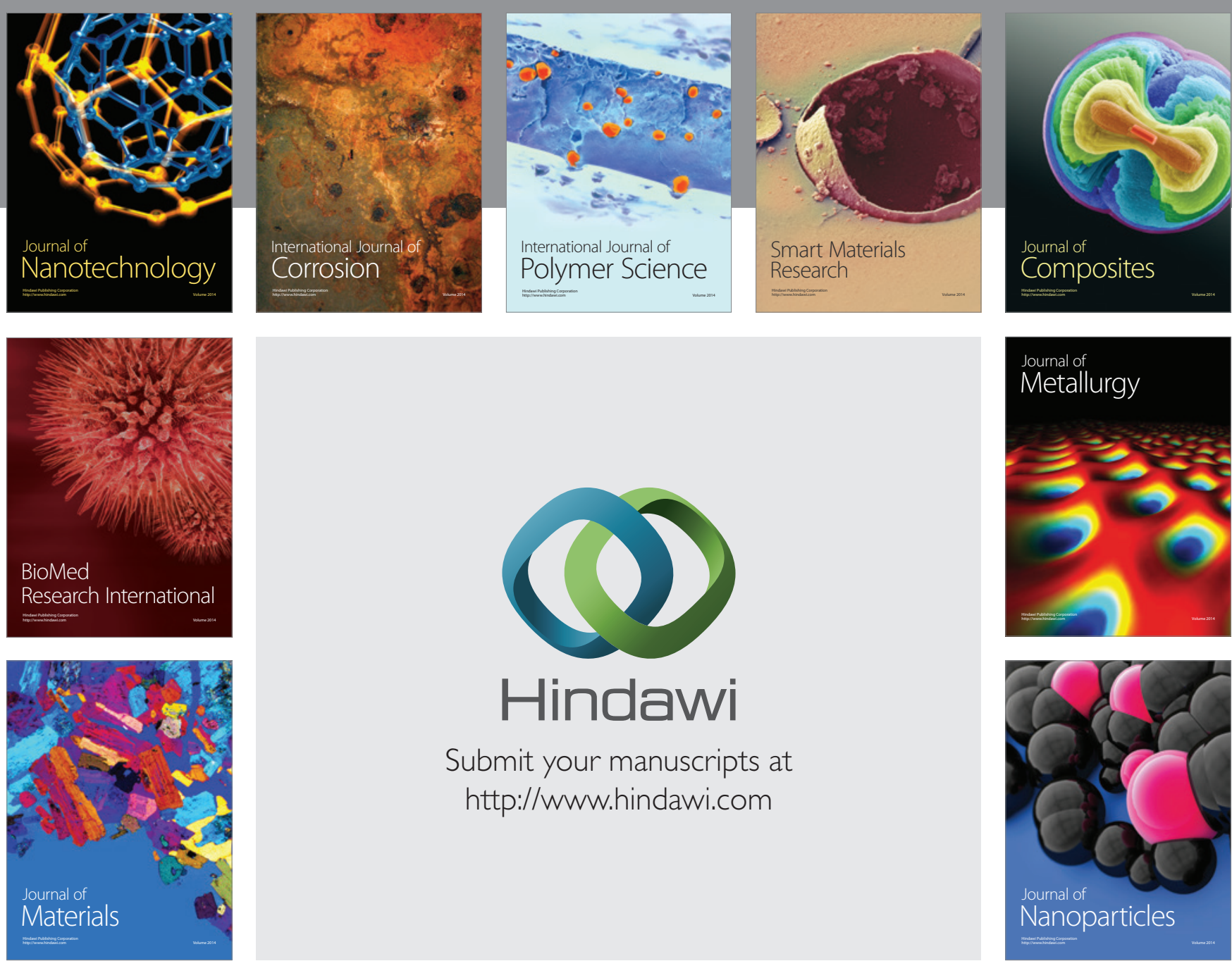

\section{Hindawi}

Submit your manuscripts at

http://www.hindawi.com

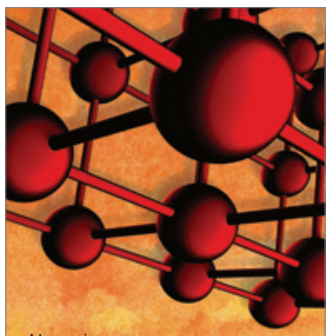

Materials Science and Engineering
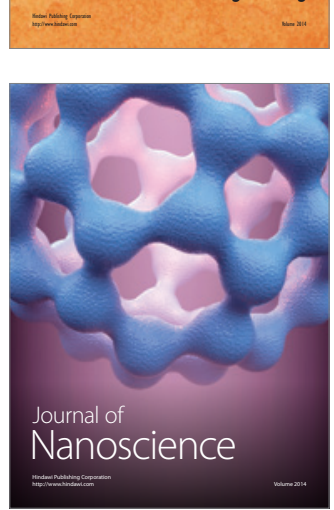
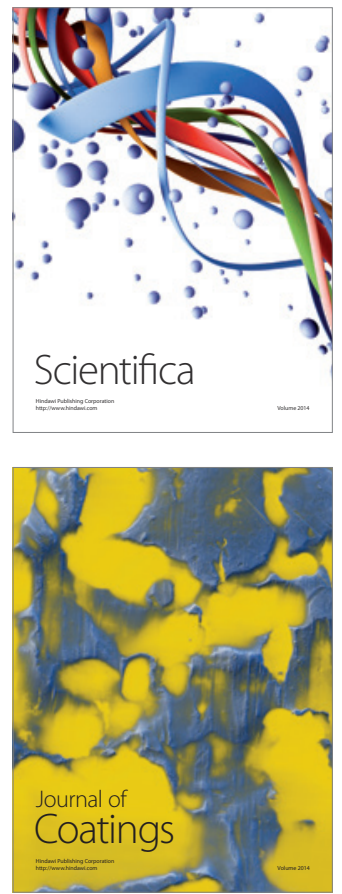
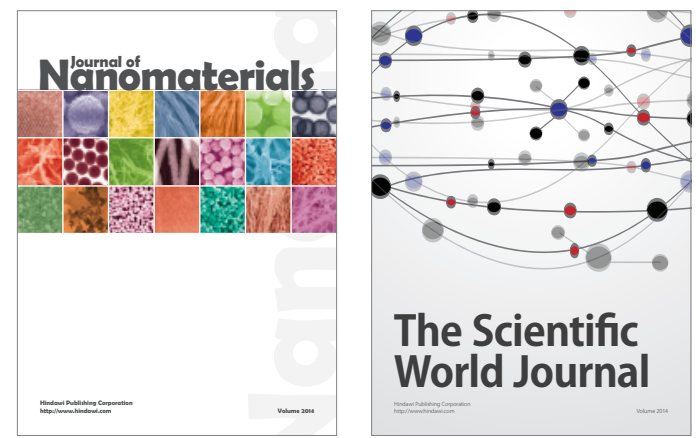

The Scientific World Journal
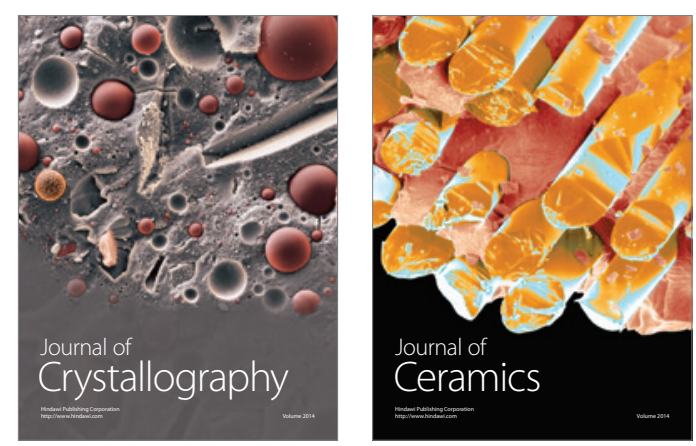
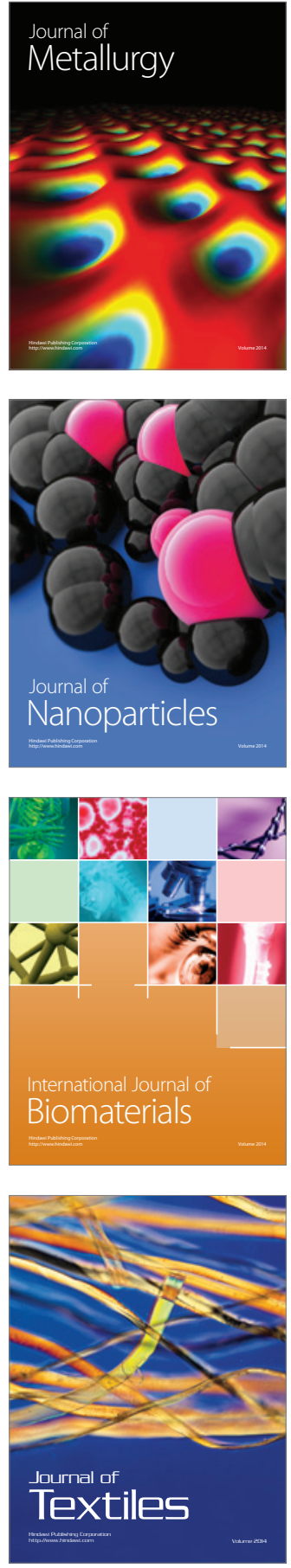